\title{
Reconciling modeled and observed temperature trends over Antarctica
}

\author{
N. Calvo, ${ }^{1,2,3}$ R. R. Garcia, ${ }^{2}$ D. R. Marsh, ${ }^{2}$ M. J. Mills, ${ }^{2}$ D. E. Kinnison, ${ }^{2}$ and P. J. Young ${ }^{4,5}$ \\ Received 26 May 2012; revised 18 July 2012; accepted 19 July 2012; published 28 August 2012.
}

[1] Over the last three decades, ozone depletion over Antarctica has affected temperature and winds in the lower stratosphere, and even in the troposphere and at the surface. The second Chemistry Climate Model Validation activity (CCMVal2) concluded that chemistry-climate models simulate stratospheric cooling that is too large compared to observations, even though the modeled and observed ozone trends are similar. However, these comparisons were based only on radiosonde data available for 1969-1998. Here, we investigate trends in the Southern Hemisphere polar cap in the latest version of the Community Earth System Model (CESM1) with its high-top atmospheric component, WACCM4, fully coupled to an ocean model. We compare model trends with observations for different periods and with other modeling studies to show much better agreement with more recent data, and conclude that the discrepancy between observed trends and those calculated by high-top models may not be as large as previously reported. Citation: Calvo, N., R. R. Garcia, D. R. Marsh, M. J. Mills, D. E. Kinnison, and P. J. Young (2012), Reconciling modeled and observed temperature trends over Antarctica, Geophys. Res. Lett., 39, L16803, doi:10.1029/ 2012 GL052526.

\section{Introduction}

[2] Observations over the last few decades have shown a significant cooling of the upper troposphere and lower stratosphere (UTLS) in the Southern Hemisphere (SH) polar cap during austral spring, together with negative trends in geopotential height that extend into the troposphere [Thompson and Solomon, 2002, 2005; Randel et al., 2009]. Calculations with General Circulation Models have corroborated these results [e.g., Gillett and Thompson, 2003] and indicated that stratospheric ozone depletion is the main driver of SH trends in the troposphere and lower stratosphere during spring and summer months [Polvani et al., 2010; McLandress et al., 2011]. The decrease in ozone in austral

\footnotetext{
${ }^{1}$ Departamento Fisica de la Tierra II, Universidad Complutense de Madrid, Madrid, Spain.

${ }^{2}$ Atmospheric Chemistry Division, National Center for Atmospheric Research, Boulder, Colorado, USA.

${ }^{3}$ Advanced Study Program, NCAR, Boulder, Colorado, USA.

${ }^{4}$ Cooperative Institute for Research in the Environmental Sciences, University of Colorado Boulder, Boulder, Colorado, USA.

${ }^{5}$ Chemical Sciences Division, NOAA Earth System Research Laboratory, Boulder, Colorado, USA.
}

Corresponding author: N. Calvo, Departamento Física de la Tierra II, Universidad Complutense de Madrid, Avda. Complutense sn, ES-28040 Madrid, Spain. (calvo@ucar.edu)

(C)2012. American Geophysical Union. All Rights Reserved. 0094-8276/12/2012GL052526 spring leads to a cooling of the lower stratosphere, accompanied by a modulation of the zonal-mean zonal winds in both the stratosphere and the troposphere during summer [Gillett and Thompson, 2003]. These changes have a large impact on tropospheric climate; e.g., they affect surface temperatures, the extent of sea ice [Thompson and Solomon, 2002], the variability of storm tracks [Yin, 2005], and the strength of the wind-driven oceanic circulation [Russell et al., 2006]. Therefore, it is important to be able to model accurately past changes in stratospheric ozone, temperature and winds in order to predict changes in $\mathrm{SH}$ tropospheric climate in the coming decades.

[3] Temperature and geopotential trends have been evaluated in Chemistry Climate Models (CCMs) that were part of the second CCM Validation activity (CCMVal2) of SPARC (Stratospheric Processes and Their Role in Climate). The CCMVal2 report [Eyring et al., 2010, chapter 10] compares modeled trends with the findings of Thompson and Solomon [2002] (hereinafter TS02), who used radiosonde data for 1969 through 1998 to calculate a linear temperature trend in the month of November of as much as $-6.5 \mathrm{~K}$ per 30 years (nearly $-2.2 \mathrm{~K}$ per decade) at about $100 \mathrm{hPa}$. The CCMVal2 models are able to reproduce the observed spatial and temporal structure of the trends in temperature and geopotential height. Nevertheless, the SPARC report concluded that the CCMVal2 models produce more stratospheric cooling for a given ozone decrease compared to TS02. CCMVal2 models should be well suited to calculate the response to perturbations in stratospheric ozone since they have fully coupled radiation, chemistry and dynamics, high vertical resolution in the stratosphere, and a top located well above the stratopause. However, these models were not coupled to deep ocean models but instead were run with specified observed sea surface temperatures. While the lack of ocean coupling has been cited as a possible reason for the discrepancy between CCMVal2 models and the results of TS02, Sigmond et al. [2010] showed that, in the Canadian Middle Atmosphere Model (CMAM), atmosphere-ocean coupling plays a negligible role in the atmospheric response to ozone depletion.

[4] As regards the observations themselves, a more recent paper by Thompson and Solomon [2005] (hereafter TS05), based on data from the International Global Radiosonde Archive (IGRA), reported much larger trends in temperature over the SH polar cap than did TS02. Temperatures, averaged over $60-90^{\circ} \mathrm{S}$, showed a significant cooling trend of up to $-3.75 \mathrm{~K}$ per decade for the period 1979-2003. This trend is more consistent with that computed from CCMVal2 models, which averages $-3.7 \mathrm{~K}$ per decade for the model ensemble [Eyring et al., 2010, chapter 10]. Note, however, that the latitudinal average is slightly wider for the computation of IGRA trends and the periods over which the trends 

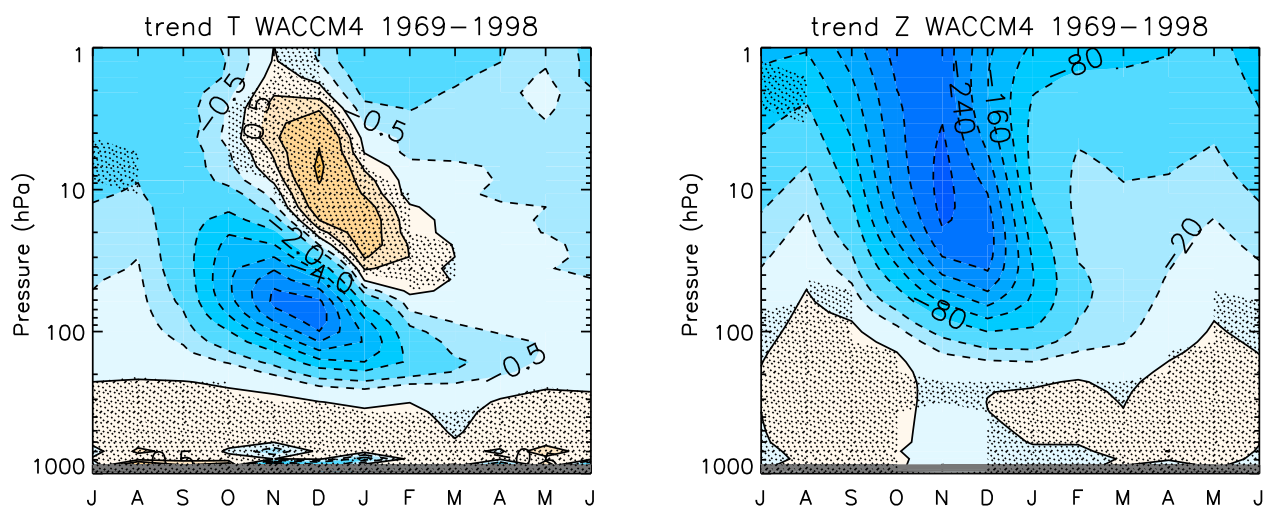

Figure 1. WACCM4 ensemble-mean trends for 1969-1998 of (left) cosine-weighted zonal-mean temperature and (right) geopotential height averaged over the polar cap $\left(65-90^{\circ} \mathrm{S}\right)$. Units are $\mathrm{K}$ per decade and $\mathrm{m}$ per decade. Contours are drawn at $0,0.5,1,2,3$, etc., $\mathrm{K}$ per decade and at $0,20,40,80,120$, etc., m per decade. Shading denotes results not significant at the $95 \%$ confidence level.

were computed are different: 1969-1998 in the analysis of TS02 vs. 1979-2003 in TS05.

[5] In the present study we analyze trends over the $\mathrm{SH}$ polar cap in the new NCAR Community Earth System Model (CESM1), using as the atmospheric component the high-top Whole Atmosphere Community Climate Model (WACCM4). WACCM4 is a fully coupled chemistryclimate model (its previous version was part of the CCMVal2 intercomparison) and, when run in the CESM1 framework, it is also coupled to a deep ocean model. We compare WACCM4 trends to different sets of observations for several periods and to previous modeling studies. It is hoped that this comparison will shed light on the uncertainties present in modeled and observational trends over Antarctica during austral spring, which has implications for predictions of the impact of stratospheric ozone recovery on the circulation of the $\mathrm{SH}$.

\section{Model and Simulations}

[6] CESM1 is a coupled climate model composed of four separate units, which simulate the atmosphere, ocean, land and sea-ice. WACCM4, the high-top atmospheric component, is a fully interactive chemistry-climate model, where radiatively active gases affect heating and cooling rates and, therefore, dynamics. The model physics is identical to that in the previous version, WACCM3.5 [Garcia et al., 2007; Marsh et al., 2007; Tilmes et al., 2007; Eyring et al., 2010]. The chemical module of WACCM4 is based on the Model of OZone and Related Tracers, version 3 (MOZART-3) [Kinnison et al., 2007]. All species in the $\mathrm{O}_{\mathrm{X}}, \mathrm{NO}_{\mathrm{X}}, \mathrm{HO}_{\mathrm{X}}$, $\mathrm{ClO}_{\mathrm{X}}$, and $\mathrm{BrO}_{\mathrm{X}}$ chemical families are included in this module, along with $\mathrm{CH}_{4}$ and its degradation products. The model domain extends from the surface to about $140 \mathrm{~km}$, with vertical resolution of about $1.25 \mathrm{~km}$ in the troposphere and lower stratosphere; $1.75 \mathrm{~km}$ in the upper stratosphere; and about $3.5 \mathrm{~km}$ in the upper mesosphere and thermosphere. The horizontal resolution is $2.5^{\circ} \times 1.9^{\circ}$ (longitude $\times$ latitude). The ocean component of CESM1 is the Parallel Ocean Program (POP), which is described in detail by Smith et al. [2010]. The performance of NCAR's coupled climate modeling system has been documented recently by Gent et al. [2011] using the Community Climate System Model, version 4 (CCSM4), which is the immediate predecessor of
CESM1 and differs minimally from the latter, except that it is able to accept WACCM as its atmospheric component.

[7] For the present study, we used an ensemble of three simulations of the period 1960-2005, which were run for the fifth Climate Model Intercomparison Project (CMIP5). All simulations used observed greenhouse gases and halogen concentrations, total spectral irradiance, geomagnetic activity and volcanic aerosols. A quasi-biennial oscillation was imposed by relaxing stratospheric tropical winds to observations, as discussed in detail by Matthes et al. [2004]. WACCM4 employs a gravity wave parameterization that accounts for waves generated by convection and frontal systems in addition to stationary orographic gravity waves [Richter et al., 2010].

\section{Results}

[8] Trends were computed for the average of the three WACCM4 ensemble members. Monthly-mean time series were averaged, weighted by the cosine of latitude, over the $\mathrm{SH}$ polar cap; then trends were determined by linear-square fits to the monthly-mean latitude-average time series. Linear trends are considered significant if different from zero at the $2 \sigma(\sim 95 \%)$ confidence level, where $\sigma$ is the standard deviation of the trend. Throughout this paper, we quote the $2 \sigma$ bounds of all linear trends we calculate. The autocorrelation of the residuals of the linear fit was taken into account when computing $\sigma$. Trends computed for individual realizations are all consistent and similar to the ensemble mean trends discussed below, although their uncertainty is larger, as expected. Still, the regions where large trends occur are significant in all realizations at the $2 \sigma$ confidence level.

[9] Figure 1 shows a time-pressure cross-section of trends in zonal mean temperature and geopotential height over the polar cap $\left(65-90^{\circ} \mathrm{S}\right)$, computed over the period 1969-1998 for direct comparison with the results of TS02. A region of large, significant cooling is present from austral spring through fall in the lower stratosphere due to ozone depletion [see, e.g., Polvani et al., 2011]. The largest trends occur in November and December and reach $-6 \mathrm{~K}$ per decade. Above the region that experiences cooling, a region of warming can be seen in the upper stratosphere, with trends up to $1.5 \mathrm{~K}$ per decade in December. This warming is of dynamical origin. The increase in the zonal-mean zonal wind 

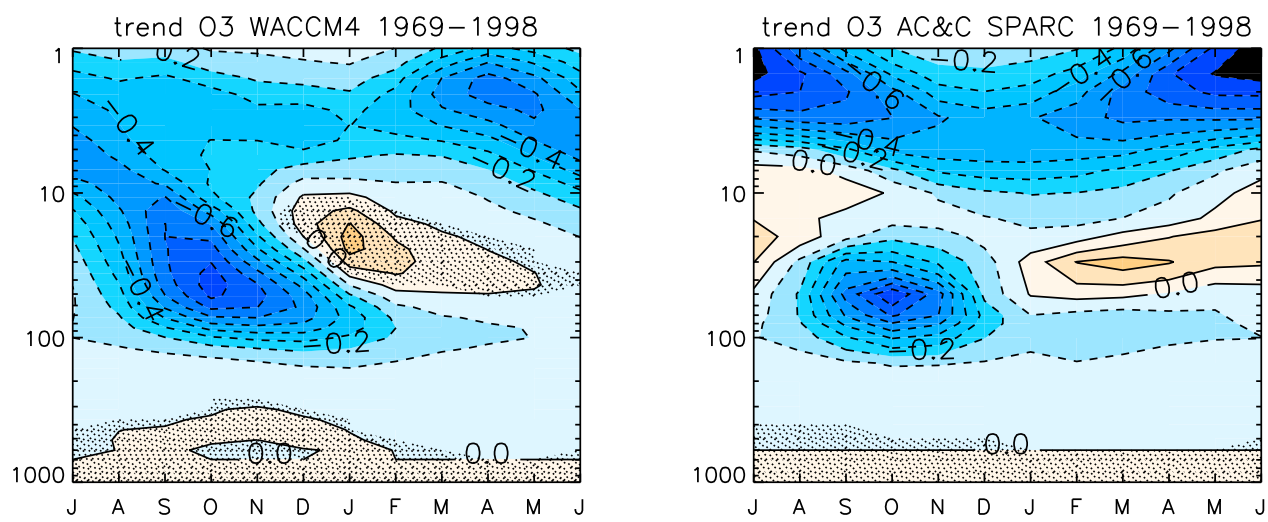

Figure 2. As in Figure 1, but for zonal-mean ozone trends in (left) WACCM4 and (right) the SPARC AC\&C data set. Units are ppmv per decade. Contours are drawn every 0.1 ppmv per decade.

associated with the temperature trend in the lower stratosphere enhances filtering of the spectrum of upward-propagating gravity waves, such that they provide a larger westerly forcing in the upper stratosphere [Manzini et al., 2003]. The cooling trend in the lower stratosphere is accompanied by significant negative trends in geopotential height in the entire polar stratosphere, which are largest (about $280 \mathrm{~m}$ per decade) around $10 \mathrm{hPa}$ in November. Significant negative trends are also present in the troposphere and even at the surface in November.

[10] We compare WACCM4 trends with the results of Thompson and Solomon [2002, Figure 1] for the period 1969-1998. The WACCM4 trends reproduce the sign and structure of the observed trends in the SH upper tropospherelower stratosphere. However, the largest modeled trends $(-6.2 \pm 2.5 \mathrm{~K}$ per decade) exceed the radiosonde trends of TS02 ( -2.2 per decade) by almost a factor of three, and the value of the observed trend lies outside the $95 \%$ uncertainty range of the model trend. It is possible that the uncertainty of the TS02 trend might overlap that of the WACCM4 trend, but we could not ascertain this because TS02 did not provide $2 \sigma$ uncertainty bounds. The largest trends in geopotential height computed with WACCM4 reach $-290 \pm 130 \mathrm{~m}$ per decade at $10 \mathrm{hPa}$ in November. TS02 do not show trends above $30 \mathrm{hPa}$; however, at $30 \mathrm{hPa}$ the trends calculated by TS02 are about $-110 \mathrm{~m}$ per decade vs. approximately -230 $\pm 100 \mathrm{~m}$ per decade in WACCM4. Thus, the observed geopotential height trend is also outside the $2 \sigma$ uncertainty range of the WACCM4 trend. In addition, the model trends persist too long into austral fall in the lower stratosphere. This behavior was also present in the previous version of WACCM, WACCM3.5, which was part of CCMVal2, and is found in other CCMs [Eyring et al., 2010, chapter 10].

[11] As mentioned in the Introduction, recent studies have attributed most of the temperature trends in austral spring to ozone changes that occurred over the past few decades in the $\mathrm{SH}$; therefore, a larger than observed ozone loss in WACCM for 1969-1998 could explain the large discrepancy with respect to TS02 over that period. Figure 2 compares timepressure cross-sections of ozone trends for the period 19691998 from the three-member WACCM4 ensemble mean with trends derived from the SPARC Atmospheric Chemistry and Climate (AC\&C) Ozone database. This database includes SAGE I + II satellite observations and polar ozonesonde measurements for the period 1979-2005, and it is extended backwards based on regression fits [Cionni et al., 2011]. In austral spring, WACCM4 reproduces the observed magnitude, timing and location of the ozone loss below about $20 \mathrm{hPa}$. The largest values, approximately $-0.8 \mathrm{ppmv}$ per decade, are found in October at about $50 \mathrm{hPa}$ in both model and observations. In January and February, there is much more ozone loss in the lower stratosphere in the model than in the observations, consistent with the persistence of negative temperature trends into these months (cf. Figure 1). This behavior is related to the fact that WACCM4 simulates too strong a winter polar vortex, which lasts into January in the lower stratosphere, contrary to what is seen in observations [see, e.g., Eyring et al., 2010, chapter 4]. Investigation of this model bias is beyond the scope of the present study. However, it is important to note that the delayed breakdown of the polar vortex cannot account for the difference between model and observations in November, when the largest trends in temperature and geopotential height occur. Therefore, the comparison shown in Figure 2 implies that differences between calculated and observed temperature and geopotential trends are unlikely to be related to biases in simulated ozone changes.

[12] We compare next the trend in WACCM4 against a more recent data set derived from IGRA radiosondes, which cover the period 1979-2003, as discussed by TS05. Figure 3 shows the WACCM4 trends for this period, averaged over $60-90^{\circ} \mathrm{S}$. The largest model trends are found at slightly higher altitude than in the observations of TS05, and have maximum values of up to $-4.6 \mathrm{~K} \pm 3.2 \mathrm{~K}$ per decade at $50 \mathrm{hPa}$ and $-200 \pm 150 \mathrm{~m}$ per decade at $10 \mathrm{hPa}$. The largest trends from IGRA are observed in November; they are $-3.75 \mathrm{~K}$ per decade at about $70 \mathrm{hPa}$ and $-200 \mathrm{~m}$ per decade at $30 \mathrm{hPa}$ Thompson and Solomon [2005, Figure 7]. Thus, the temperature and geopotential trends in WACCM4 are in much better agreement with the IGRA radiosonde data of TS05 than with the older data set used by TS02. In fact, the trends of TS05 lie within the uncertainty bounds of the WACCM4 trends (for both temperature and geopotential), so the observed and modeled trends are statistically undistinguishable from each other.

[13] The comparison between trends in WACCM4 and radiosondes from $\mathrm{TS} 02$ and $\mathrm{TS} 05$ discussed above raise 

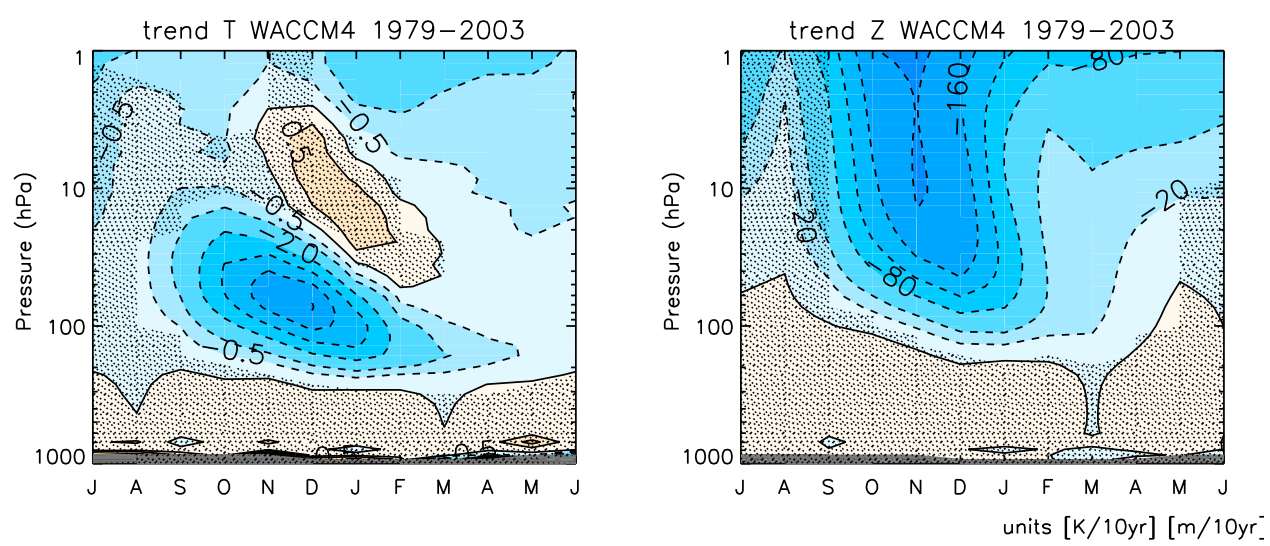

Figure 3. As Figure 1, but for $1979-2003$ and $60-90^{\circ} \mathrm{S}$ latitudinal average.

questions about the reliability of temperature trends over Antarctica. In addition to the two studies by Thompson and Solomon, there are a few published estimates of temperature change in the Antarctic lower stratosphere. One of these is the work of Randel and $W u$ [1999], who documented the evolution of temperature anomalies in November at $100 \mathrm{hPa}$ for eight radiosonde stations in Antarctica from 1955 to 1998. Randel and $W u$ [1999, Figure 4] show that temperatures remained reasonably stable through the late 1970's, after which time all stations show a more or less pronounced decline. Over 1979-1998, this decline ranged from about $-1.5 \mathrm{~K}$ per decade to $-6.5 \mathrm{~K}$ per decade. These values bracket the WACCM4 trends for either 1969-1998 or 19792003, discussed above, as well as the WACCM4 trend for $1979-1998$ at $100 \mathrm{hPa}$, which is $-4.1 \pm 2.5 \mathrm{~K}$ per decade, for the $65-90^{\circ} \mathrm{S}$ latitudinal average. This illustrates further the variability of trends calculated from the sparse set of radiosonde stations over Antarctica.

[14] We have also calculated temperature trends using publicly available data from two reanalyses: the ERAInterim data set from the European Center for MediumRange Weather Forecasts [Dee et al., 2011] and NASA's Modern ERA-Retrospective Analysis for Research and Applications (MERRA) [Rienecker et al., 2011]. These reanalyses include a large number of observations from weather stations, balloons, aircraft, ships, buoys and

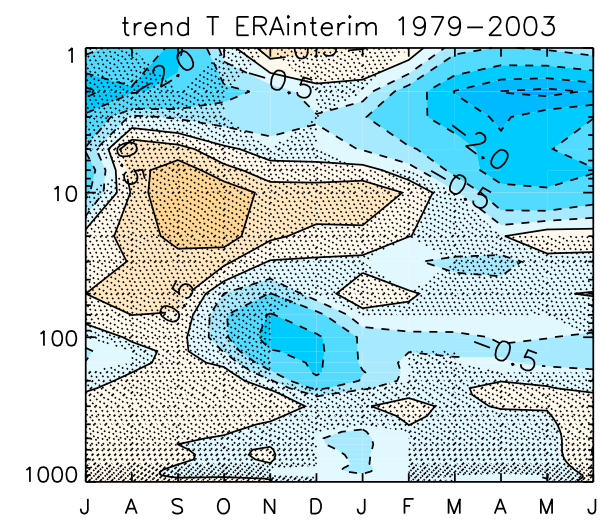

satellites. The height of the upper boundary of the models used for these reanalyses was raised compared to earlier products, which led to substantial improvements in the analyzed structure of the middle stratosphere, even in Antarctica up to $30-40 \mathrm{~km}$. Ozone is assimilated in both reanalyses. Figure 4 shows polar-cap $\left(60-90^{\circ} \mathrm{S}\right)$ temperature trends obtained from these data for 1979-2003, analogous to our Figure 3. Significant cooling, over $-2 \mathrm{~K}$ per decade, is observed at $100 \mathrm{hPa}$ during November-December in both reanalyses. These trends are about half those calculated from WACCM4 or from the IGRA radiosondes (TS05). However, these widely different values are not statistically distinguishable from each other. As a specific example, we compare polar cap $\left(60-90^{\circ} \mathrm{S}\right)$ temperatures for NovemberDecember, averaged between 50 and 150, in each of the three WACCM4 realizations, their ensemble mean, and the two reanalyses (see auxiliary material, Figure S1). ${ }^{1}$ Although interannual variability is reduced in the model ensemble mean, the long-term behavior is similar in all the realizations. The trends of these time series are $-4.2 \pm 2.8 \mathrm{~K}$ per decade for the WACCM4 ensemble mean $(-3.2 \pm 2.1,-3.6 \pm 3.1$ and $-4.5 \pm 3.2 \mathrm{~K}$ per decade for the individual realizations), $-1.7 \pm 1.9 \mathrm{~K}$ per decade for ERA-Interim and $-1.8 \pm 1.8 \mathrm{~K}$

${ }^{1}$ Auxiliary materials are available in the HTML. doi:10.1029/ 2012GL052526.

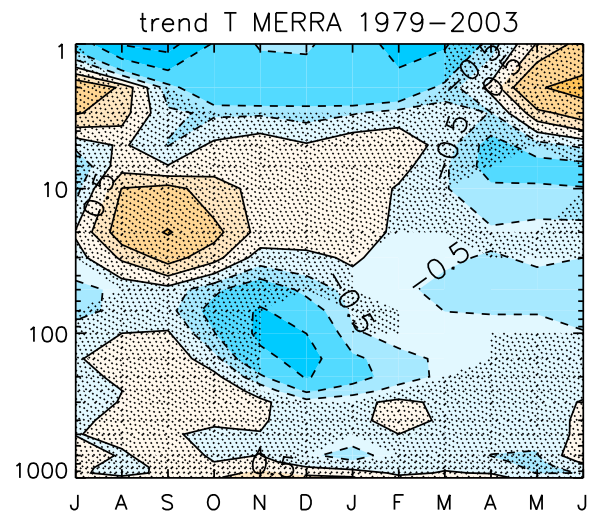

Figure 4. Trends of latitudinally averaged cosine-weighted temperature $\left(60-90^{\circ} \mathrm{S}\right)$ for (left) ERA-Interim and (right) MERRA for the period 1979-2003. Units are K per decade. Contours are drawn at 0, 0.5, 1, 2, 3 K per decade. Shading denotes not significant areas at the $95 \%$ confidence level. 
Table 1. Linear Trends Over the SH Polar Cap From Various Models and Observational Data Sets ${ }^{\mathrm{a}}$

\begin{tabular}{|c|c|c|c|}
\hline Case & $\mathrm{T}$ (K per decade & tential ( $m$ per decade) & Source \\
\hline TS02, 1969-1998 & -2.2 & -110 & Thompson and Solomon [2002] \\
\hline WACCM4, 1969-1998, 65-90 S & $-6.2 \pm 2.5$ & $-290 \pm 130$ & This work \\
\hline CCMVal2 ensemble, 1969-1998, 65-90 S & -3.7 & -166 & Eyring et al. [2010] \\
\hline TS05, 1979-2003, 60-90 S & -3.75 & -200 & Thompson and Solomon [2005] \\
\hline WACCM4, 1979-2003, 60-90 S & $-4.6 \pm 3.2$ & $-200 \pm 150$ & This work \\
\hline ERA-Interim, 1979-2003, Nov-Dec, $50-150 \mathrm{hPa}, 60-90 \mathrm{~S}$ & $-1.8 \pm 3.1$ & & Dee et al. [2011] \\
\hline MERRA, 1979-2003, Nov-Dec, 50-150 hPa, 60-90 S & $-1.9 \pm 3.0$ & & Rienecker et al. [2011] \\
\hline WACCM4 ensemble,1979-2003, Nov-Dec, $50-150 \mathrm{hPa}, 60-90 \mathrm{~S}$ & $-3.7 \pm 2.6$ & & This work \\
\hline CMAM, 1960-1999, 70-90 S & -5.5 & & McLandress et al. [2011] \\
\hline WACCM4, 1960-1999, 70-90 S & $-5.5 \pm 2.5$ & & This work \\
\hline IUK, 1969-1998 & $-4.7 \pm 2.8$ & & Young et al. [2012, submitted manuscript] \\
\hline RICH-obs, 1969-1998 & $-4.1 \pm 2.4$ & & Young et al. [2012, submitted manuscript] \\
\hline HadAT2 , 1969-1998 & $-3.8 \pm 2.4$ & & Young et al. [2012, submitted manuscript] \\
\hline
\end{tabular}

\footnotetext{
${ }^{\mathrm{a}}$ The maximum trend attained between September and January between the surface and $10 \mathrm{hPa}$ is given, unless otherwise indicated. $2 \sigma$ errors are also
} shown where available.

per decade for MERRA. While the WACCM4 trends are substantially larger than those computed from either reanalysis, the $2 \sigma$ errors are so large that the trends cannot be statistically distinguished at the $95 \%$ confidence level.

\section{Summary and Discussion}

[15] NCAR's Community Earth System Model, with the high-top atmospheric component, WACCM4, simulates significant cooling over the SH polar cap in the UTLS in response to ozone depletion, accompanied by significant negative trends in geopotential height. These changes are in line with previous studies of the role of ozone depletion in SH climate. However, the largest trends in WACCM4 $(-6.2 \mathrm{~K}$ per decade) are almost three times larger than the 1969-1998 trends derived by Thompson and Solomon [2002] from radiosonde data $(-2.2 \mathrm{~K}$ per decade), which have become a benchmark for the analysis of trends over Antarctica. The observed trend lies outside the $2 \sigma$ uncertainty range of the trend in WACCM4, despite the fact that the model simulates well the observed Antarctic ozone loss for the same period. On the other hand, temperature and geopotential trends computed from IGRA radiosonde data for 1979-2003 [Thompson and Solomon, 2005] are very similar to, and statistically undistinguishable from, the corresponding trends from WACCM4. Model trends are also statistically undistinguishable from trends computed from ERA-Interim and MERRA reanalyses, even though the largest trends in the reanalyses are about half those simulated in WACCM4. Recently, P. J. Young et al. (Late twentieth century Southern Hemisphere stratospheric temperature trends in observations and CCMVal-2, CMIP3 and CMIP5 models, submitted to Journal of Geophysical Research, 2012) estimated Antarctic temperature trends from several radiosonde data sets. For the period 1969-1998, they found cooling in November, at $100 \mathrm{hPa}$, ranging from $-3.8 \pm 2.4$ to $-4.7 \pm 2.8 \mathrm{~K}$ per decade. These values are about twice as large as the trend derived by TS02 and statistically indistinguishable from WACCM4 trends at the $95 \%$ confidence level. Note that the largest trend in WACCM4 is actually found near $70 \mathrm{hPa}$; at $100 \mathrm{hPa}$, the November trend computed by the model is about $-4 \mathrm{~K}$ per decade (cf. Figure 1).

[16] WACCM4 results are also consistent with those from other CCMs. McLandress et al. [2011] analyzed a simulation performed with the Canadian Middle Atmosphere Model (CMAM) coupled to an ocean, with greenhouse gases and ozone depleting substances prescribed from observations. CMAM polar cap $\left(70-90^{\circ} \mathrm{S}\right)$ temperature trends for 1960-1999 peak at $-5.5 \mathrm{~K}$ per decade, in excellent agreement with the corresponding WACCM4 trends, $-5.5 \pm$ $2.5 \mathrm{~K}$ per decade. The maximum cooling trend in the SPARC CCMVal2 ensemble for 1969-1998 over the SH polar cap is $-3.7 \mathrm{~K}$ per decade with model performance falling into two groups: a cluster that produce ozone trends consistent with observations but overestimate temperature trends and another group that simulates temperature trends closer to observations but ozone trends that are too small [cf. Eyring et al., 2010, Figure 10.13].

[17] In summary, the results presented here suggest that SH polar cap trends obtained from CCMs in general, and WACCM4 in particular, may not be significantly different from the trends derived from observations; this conclusion coincides with the findings of Young et al. (submitted manuscript, 2012) mentioned above. In most of the examples discussed here, which are summarized in Table 1, the trends calculated with WACCM4 are either in agreement with the observed trends, or they are larger but not statistically different from them. The one exception is the trend for the period 1969-1998, which in WACCM4 is almost a factor of three larger than that derived by TS02 from Antarctic radiosonde data. It is important to note that we have used model zonal mean trends to compare with observations, which are typically poorly sampled. While temperature trends over Antarctica display strong zonal asymmetries in September and October, this is not the case in November and December, when the largest trends occur [cf. Fu et al., 2010]. Thus, zonal asymmetries in the trends are unlikely to be a major contributor to the differences reported here (see Young et al. [2012] for a more detailed discussion).

[18] Despite the large uncertainties associated with temperature trends computed from observational data, it is still possible that WACCM4 might overestimate those trends, even though it produces ozone trends consistent with observations. A strengthening of the mean meridional downwelling over Antarctica after the inception of the ozone hole could compensate in part for reduced shortwave heating due to ozone loss and lead to a smaller temperature response. However, none of the WACCM4 realizations show a trend in the mean meridional circulation in the Antarctic lower stratosphere during the months when the largest temperature trends occur (not shown). Similar behavior is present in most 
CCMVal2 models, as pointed out by Wang and Waugh [2012]. Among thirteen models reviewed in Eyring et al. [2010] for which trends in the meridional circulation were available, we found only one (SOCOL) that showed a significant positive trend in the lower stratosphere in OctoberNovember. However, while SOCOL produces a temperature trend consistent with TS02, its trend in Antarctic ozone is much smaller than observed. Mean meridional downwelling cannot be observed directly, and the vertical velocity produced by reanalysis models is too unreliable to establish the existence of any trends, so it is difficult to ascertain whether there has actually been any change in the mean meridional circulation over Antarctica. Analyses using temperature as an indirect measure of the meridional circulation suggest a strengthening of the $\mathrm{SH}$ branch of the circulation during austral winter and spring [e.g., Young et al., 2012], although the strong radiative cooling from ozone depletion complicates this analysis.

[19] The large differences between trends obtained from observational data sets, together with the ambiguities surrounding the possible role of the mean meridional circulation in Antarctica suggest that additional observational and the modeling work is needed to quantify precisely recent trends in Antarctica and understand their origin. This would appear to be a prerequisite for accurate prediction of climate change in the Southern Hemisphere as the halogen load of the atmosphere decreases while that of greenhouse gases increases in the course of the 21 st century.

[20] Acknowledgments. N. Calvo was partially supported by the Advanced Study Program from the National Center for Atmospheric Research (ASP-NCAR) and by the Spanish Ministry of Science and Innovation through the CGL2008-05968-C02-01 project. NCAR is sponsored by the U.S. National Science Foundation.

[21] The Editor thanks the two anonymous reviewers for their assistance in evaluating this paper.

\section{References}

Cionni, I., et al. (2011), Ozone database in support of CMIP5 simulations: Results and corresponding radiative forcing, Atmos. Chem. Phys. Discuss., 11, 10,875-10,933, doi:10.5194/acpd-11-10875-2011.

Dee, D. P., et al. (2011), The ERA-Interim reanalysis: Configuration and performance of the data assimilation system, Q. J. R. Meteorol. Soc., 137, 553-597, doi:10.1002/qj.828.

Eyring, V., T. G. Shepherd, and D. W. Waugh (Eds.) (2010), SPARC report on the evaluation of chemistry climate models, SPARC Rep. 5, World Clim. Res. Programme, World Meteorol. Organ., Geneva, Switzerland. [Available at http://www.sparc-climate.org/publications/sparc-reports/.]

Fu, Q., S. Solomon, and P. Lin (2010), On the seasonal dependence of tropical lower-stratospheric temperature trends, Atmos. Chem. Phys., 10, 2643-2653, doi:10.5194/acp-10-2643-2010.

Garcia, R. R., D. Marsh, D. E. Kinnison, B. Boville, and F. Sassi (2007), Simulations of secular trends in the middle atmosphere, 1950-2003, J. Geophys. Res., 112, D09301, doi:10.1029/2006JD007485. Gent, P. R., et al. (2011), The Community Climate System Model version 4, J. Clim., 24, 4973-4991, doi:10.1175/2011JCLI4083.1.

Gillett, N. P., and D. W. J. Thompson (2003), Simulations of recent Southern Hemisphere climate change, Science, 302(5643), 273-275, doi:10.1126/ science. 1087440 .
Kinnison, D. E., et al. (2007), Sensitivity of chemical tracers to meteorological parameters in the MOZART-3 chemical transport model, J. Geophys. Res., 112, D20302, doi:10.1029/2006JD007879.

Manzini, E., B. Steil, C. Bruhl, M. A. Giorgetta, and K. Kruger (2003), A new interactive chemistry-climate model: 2 . Sensitivity of the middle atmosphere to ozone depletion and the increase in greenhouse gases and implications for recent stratospheric cooling, J. Geophys. Res., 108 (D14), 4429, doi:10.1029/2002JD002977.

Marsh, D. R., R. R. Garcia, D. E. Kinnison, B. A. Boville, S. Walters, K. Matthes, and S. C. Solomon (2007), Modeling the whole atmosphere response to solar cycle changes in radiative and geomagnetic forcing, J. Geophys. Res., 112, D23306, doi:10.1029/2006JD008306.

Matthes, K., U. Langematz, L. L. Gray, K. Kodera, and K. Labitzke (2004), Improved 11-year solar signal in the Freie Universität Berlin Climate Middle Atmosphere Model (FUB-CMAM), J. Geophys. Res., 109, D06101, doi:10.1029/2003JD004012.

McLandress, C., T. G. Shepherd, J. F. Scinocca, D. A. Plummer, M. Sigmond, A. I. Jonsson, and M. C. Reader (2011), Separating the dynamical effects of climate change and ozone depletion. Part II: Southern Hemisphere troposphere, J. Clim., 24, 1850-1868, doi:10.1175/2010JCLI3958.1.

Polvani, L. M., D. W. Waugh, G. J. P. Correa, and S. W. Son (2011), Stratospheric ozone depletion: The main driver of 20th century atmospheric circulation changes in the Southern Hemisphere, J. Clim., 24, 795-812, doi:10.1175/2010JCLI3772.1.

Randel, W. J., and F. Wu (1999), Cooling of the Arctic and Antarctic polar stratospheres due to ozone depletion, J. Clim., 12, 1467-1479, doi:10.1175/1520-0442(1999)012<1467:COTAAA >2.0.CO;2.

Randel, W. J., et al. (2009), An update of observed stratospheric temperature trends, J. Geophys. Res., 114, D02107, doi:10.1029/2008JD010421.

Richter, J. H., F. Sassi, and R. R. Garcia (2010), Toward a physically based gravity wave source parameterization in a general circulation model, J. Atmos. Sci., 67, 136-156, doi:10.1175/2009JAS3112.1.

Rienecker, M. M., et al. (2011), MERRA: NASA's modern-era retrospective analysis for research and applications, J. Clim., 24, 3624-3648, doi:10.1175/JCLI-D-11-00015.1.

Russell, J. K., W. Dixon, A. Gnanadesikan, R. J. Stouffer, and J. R. Toggweiler (2006), The Southern Hemisphere westerlies in a warming world: Propping open the door to the deep ocean, J. Clim., 19, 6382-6390, doi:10.1175/JCLI3984.1.

Sigmond, M., J. C. Fyfe, and J. F. Scinocca (2010), Does the ocean impact the atmospheric response to stratospheric ozone depletion?, Geophys. Res. Lett., 37, L12706, doi:10.1029/2010GL043773.

Smith, R. D., et al. (2010), The Parallel Ocean Program (POP) reference manual, Tech. Rep. LAUR-10-01853, Los Alamos Natl. Lab., Los Alamos, N. M.

Thompson, D. W. J., and S. Solomon (2002), Interpretation of recent Southern Hemisphere climate change, Science, 296, 895-899, doi:10.1126/ science. 1069270 .

Thompson, D. W. J., and S. Solomon (2005), Recent stratospheric climate trends as evidence in radiosonde data: Global structure and tropospheric linkages, J. Clim., 18, 4785-4795, doi:10.1175/JCLI3585.1.

Tilmes, S., D. E. Kinnison, R. R. Garcia, R. Müller, F. Sassi, D. R. Marsh, and B. A. Boville (2007), Evaluation of heterogeneous processes in the polar lower stratosphere in the Whole Atmosphere Community Climate Model, J. Geophys. Res., 112, D24301, doi:10.1029/2006JD008334.

Wang, L., and D. W. Waugh (2012), Chemistry-climate model simulations of recent trends in lower stratospheric temperatures and stratospheric residual circulation, J. Geophys. Res., 117, D09109, doi:10.1029/ 2011JD017130.

Yin, J. H. (2005), A consistent poleward shift of the storm tracks in simulations of the 21 st century climate, Geophys. Res. Lett., 32, L18701, doi:10.1029/2005GL023684.

Young, P. J., K. H. Rosenlof, S. Solomon, S. C. Sherwood, Q. Fu, and J.-F. Lamarque (2012), Changes in stratospheric temperatures and their implications for changes in the Brewer-Dobson circulation, 1979-2005, J. Clim., 25, 1759-1772, doi:10.1175/2011JCLI4048.1. 